\title{
Bevacizumab/Cetuximab/Irinotecan Regimen
}

National Cancer Institute

\section{Source}

National Cancer Institute. Bevacizumab/Cetuximab/Irinotecan Regimen. NCI Thesaurus. Code $C 37554$

A chemotherapy regimen consisting of bevacizumab, cetuximab and irinotecan that may be used in the treatment of colorectal cancer. 